\title{
Hacia un nuevo modelo de comunicación lexicográfica en el ámbito de la adquisición de lenguas extranjeras
}

\author{
ALBERTO GALVÁN-SANTANA \\ Universidad de Las Palmas de Gran Canaria \\ albertop.galvan@ulpcg.es
}

Recientes desarrollos en el ámbito de la Lingüística Cognitiva han estimulado en la investigación lexicográfica el interés y la necesidad de una motivación psico-cognitiva en la conceptualización del diccionario orientado a la adquisición y aprendizaje de lenguas. El presente artículo se erige como un intento de articular una respuesta a esta demanda desde el punto de vista de la comunicación, fundamentado sobre el supuesto teórico de una relación de concomitancia entre el procesamiento cognitivo y comunicativo de las estructuras lingüísticas (Zeige 2011: 49) ${ }^{1}$.

A este respecto, el modelo de comunicación lexicográfica elaborado por Yong y Peng (2007) sirve como punto de partida para esta propuesta de análisis basada, no en la disparidad de los esquemas metafóricos aplicados para el estudio del fenómeno de la comunicación - metáforas de la transmisión y de la conversación-, sino en la divergencia de los principios teórico-filosóficos subyacentes: lógicas equivalencial y diferencial del conocimiento. La consideración de aspectos comunicativos del medio lexicográfico bajo esta perspectiva abre nuevos caminos para la integración de aspectos psico-cognitivos en el análisis del potencial didáctico del diccionario lingüístico monolingüe en el ámbito de la enseñanza-aprendizaje de la lengua extranjera.

\section{INTRODUCCIÓN}

Los métodos, procesos y resultados de toda investigación científica se ven supeditados al marco interpretativo general utilizado como sistema de referencia. Estas herramientas o estrategias heurísticas facilitan y condicionan el acceso conceptual al objeto de estudio, abren procedimientos de análisis divergentes y conducen a la elaboración de hipótesis y propuestas resolutivas diferentes. Al igual que en el resto de ámbitos de la ciencia, el estudio de las teorías de la comunicación suele recurrir a esquemas interpretativos para la explicación del fenómeno comunicativo, mediante los cuales se conceptualizan, organizan y explican sus principales atributos. Entre los esquemas interpretativos más extendidos se encuentra el de la transmisión de información, el cual activa un conjunto de determinados procesos e implicaciones metafóricas latentes (Lakoff y Johnson 1980). La investigación lexicográfica, en su intento por considerar aspectos pragmáticos y socio-culturales en el proceso de realización de diccionarios, ha adoptado acercamientos teóricos desde el ámbito del estudio de la comunicación como

\footnotetext{
${ }^{1}$ Mi agradecimiento a Jorge Juan Vega por su consejo y sus interesantes comentarios en la elaboración de este artículo.

ALBERTO GALVÁN-SANTANA, 
proceso de intercambio de información, asumiendo y aplicando los fundamentos interpretativos subyacentes.

La propuesta desarrollada en el presente artículo, sin embargo, diverge en su enfoque interpretativo de este acercamiento convencional y pretende explorar nuevos modelos explicativos de la comunicación lexicográfica. En este sentido, entendemos que la aplicación de marcos explicativos teórico-filosóficos ofrece una mayor adecuación de los métodos de análisis a las características constitutivas del texto lexicográfico. El presente acercamiento investigativo pretende explorar nuevas estrategias heurísticas que enriquezcan y amplíen la discusión en torno a los modelos de comunicación lexicográfica. El objetivo es abordar y profundizar desde esta nueva perspectiva en aspectos relacionados con el potencial didáctico del diccionario lingüístico monolingüe en el ámbito de la enseñanza-aprendizaje de las lenguas extranjeras.

\section{LA METAFÓRICA DE LOS MODELOS COMUNICATIVOS}

Aguado (2004: 17-19) enmarca los esquemas mentales interpretativos en el plano lingüístico-cognitivo de la metáfora. A este respecto habla Aguado de dos encuadres metafóricos dominantes a la hora de abordar el análisis del hecho comunicativo: la metáfora del intercambio o transacción y la metáfora de la conversación. De acuerdo con la metáfora del intercambio la información es considerada como un producto exclusivo del emisor. El emisor codifica la información en un mensaje que se presenta como «unidad de intercambio» (2004: 18) y es transferida al receptor para su decodificación. Esta transmisión tiene lugar en un entorno de ruido como factor de perturbación. La metáfora de la conversación, por otro lado, alude al papel crucial que se concede a la situación comunicativa en la (re-)construcción de la información por los sujetos participantes en la comunicación.

El marco general descriptivo expresado a través de esta visualización metafórica se encuadra en la clasificación de las principales teorías sobre la comunicación presentada por Fiske (1982) bajo dos enfoques divergentes: el enfoque procesal (metáfora del intercambio) y el enfoque semiótico (metáfora de la conversación). Los principios subyacentes a esta clasificación - «escuela centrada en el proceso» vs. «escuela semiótica» (1982: XX)-, y que a continuación se detallan, marcan el punto de enlace conceptual entre el acercamiento tradicional y el planteamiento articulado sobre el binomio lógica equivalencial-lógica diferencial que se defiende en este artículo.

El primer enfoque descrito por Fiske se centra en el proceso, «por el cual una persona influye en el comportamiento o estado mental de otra», y considera la comunicación como una «transmisión de mensajes» (1982: XX). Este planteamiento representa una comprensión mecanicista y unidireccional del hecho comunicativo, entendido como acto de comunicación, y centra su interés en el grado de eficacia y precisión en la sucesión de niveles que constituyen el proceso activo de transmisión. Fundamentos categoriales de causalidad subyacen a la conceptualización de esta tendencia: se analiza el efecto que la comunicación, en cuanto acción, ocasiona en el destinatario del mensaje, receptor pasivo de un significado unívoco e invariable. De acuerdo con la escuela procesal, un mensaje es lo que el emisor quiere transmitir codificando la información en un soporte material (acústico, visual, etc.). Muchos de los autores de esta escuela 
consideran que la intención es un criterio decisivo en la constitución del mensaje: «[1]a intención del emisor puede ser explícita o implícita, consciente o inconsciente, pero debe ser recuperable mediante el análisis» (Fiske 1982: XXI).

El segundo enfoque concibe la comunicación como «producción e intercambio de sentido», y utiliza la semiótica como método de análisis en lo que concierne a «la forma como los mensajes, los textos, interactúan con las personas para producir sentido» (1982: XX). Frente a la concepción esencialista, la escuela semiótica entiende el mensaje como una «construcción de signos» (XXI) que produce significados en interacción con los receptores. En palabras de Eco y Fabbri los sujetos participantes en el hecho comunicativo no disponen de códigos, sino de una competencia textual, un conjunto de «prácticas textuales depositadas» culturalmente que les permite interpretar los «conglomerados textuales» a los cuales se ven expuestos (Eco y Fabbri 1978: 563). Se realza la importancia del texto y de "cómo es leído», en cuanto que la lectura hace referencia a la constitución de los significados que afloran durante la interacción o negociación del lector con el texto. Esta búsqueda permanente de pacto con el texto se produce en la medida que el lector contribuye con aspectos de su experiencia cultural a la composición de los signos y códigos que conforman ese texto. El mensaje, por lo tanto, no es un elemento «enviado de A a B», sino un componente en una relación textualizada de significados cuyos demás componentes incluyen la realidad exterior y el productor/lector (Fiske 1982: XXI). Esta orientación semiótica delimita el área de estudio en torno al significado que emana de los textos. Esta área de estudio integra la negociación y la circulación de este significado entre el texto y su con-texto socio-cultural, así como a su potencial a la hora de influir e interaccionar con la comunidad socio-cultural que los produce (comp. Greenblatt 1988: 7). El estudio de la comunicación se identifica así con el análisis de aquella urdimbre de significados que entrelaza y vincula en un mismo tejido el texto y la cultura. El mensaje, al contrario que para la escuela procesal, no es una información referente a una realidad externa enviada por un emisor a un receptor. Al contrario, el mensaje se concibe en el enfoque semiótico como un elemento más de significación, el cual se integra en una constelación de sentido creada e interpretada como realidad en el marco de la interacción social.

\section{EL MODELO DE COMUNICACIÓN LEXICOGRÁFICA DE YONG Y PENG}

Con el objetivo de una mejor identificación de las divergencias, tanto en sus premisas como en sus consecuencias heurísticas, entre los enfoques tradicionales y el acercamiento aquí propuesto, se construirá la argumentación sobre la base de la clasificación que establecen Yong y Peng para la explicación de su modelo comunicativo (2007: 1-10). Yong y Peng sitúan la dimensión medial de los diccionarios en el centro de sus análisis y propugnan la consolidación de un modelo comunicativo lexicográfico. En este sentido, los autores perfilan las bases de su enfoque comunicativo en relación con diferentes perspectivas sobre el medio lexicográfico en función de la orientación teórica aplicada: «diccionario como obra de referencia», «diccionario como texto» y «diccionario como comunicación» (2007: 1-6). 


\subsection{El acercamiento clásico: diccionario como obra de referencia}

Un acercamiento tradicional consiste en la concepción «limitada» (2007: 3) del diccionario como una obra de consulta. El diccionario pone a disposición del usuario una selección de palabras en un listado alfabéticamente ordenado, a las que se añade una información complementaria en lo que concierne a su ortografía, pronunciación, definición, etc. «All this points to the fact that the reference function is what most lexicographers strive to enable their products to fulfil» (ibid.). Sobre la base de esta función primordial los diccionarios adquieren una funcionalidad complementaria en la medida que pueden proporcionar un sistema de descripción de una lengua extinta, aportar directrices para el uso correcto de la lengua en su trasfondo social, o servir de instrumento ideológico portador de unas doctrinas y valores morales determinados, entre otros elementos.

\subsection{Lexicografía y tipología textual: diccionario como texto}

Una segunda perspectiva en la consideración de la obra lexicográfica se fundamenta en una metodología de análisis desarrollada en el ámbito de la Tipología Textual. La comunicación lexicográfica queda restringida en su dimensión textual a la descripción proposicional ofrecida en la microestructura. En este «textual approach» Yong y Peng presentan un acercamiento al diccionario como texto con consonancia con las consideraciones de Frawley (1989), quien postula la incorporación de los criterios de textualidad desarrollados por Beaugrande para el escrutinio de la definición lexicográfica en función de su articulación proposicional. Los esquemas de integración desconocido-conocido junto con un incremento de la cohesión textual favorecen, según Frawley, la procesabilidad, desde un punto de vista cognitivo, del contenido informativo presentado en el artículo lexicográfico. Estos esquemas promoverían un grado óptimo de accesibilidad cognitiva, una orientación infra-considerada en la investigación lexicográfica (1989: 246).

\subsection{El intercambio de información: diccionario como comunicación}

Bajo la designación «communicative approach» Yong y Peng argumentan en tercer lugar el carácter comunicativo del diccionario de acuerdo con el modelo jakobsoniano de comunicación (1981). De este modo, los autores se decantan por una conceptualización mecanicista de la escuela procesal frente a los principios teóricos de la escuela semiótica: «dictionary making is by its very nature a process of transmitting and imparting knowledge and information and [...] lexicography studies how this process is realized» (Yong y Peng 2007: 7).

Partiendo de un enfoque procesal el modelo de Jakobson establece un gradiente de unión entre los postulados de las dos escuelas al proponer al receptor como elemento activo del proceso comunicativo (Fiske 1982: 35). Jakobson extrae el elemento de la información de la linealidad del proceso esbozado por Shannon y Weaver (1949) —en el cual la información está contenida en el mensaje-, mediante la consideración de dos factores constitutivos adicionales: por un lado, el contexto referencial, y, por otro lado, el código, entendido como un conjunto de signos - compartido por el emisor y el receptor-, relacionados entre sí. Este corpus significativo está sujeto a «reglas o convenciones que determinan en qué contexto se utilizan estos signos y cómo pueden ser combinados para formar mensajes más complejos» (Fiske 1982: 14), y proporciona el 
marco convencional de sentido que confiere la significación al signo concreto. En este sentido, el intercambio de mensajes entre un emisor y un receptor requiere para su funcionalidad de tres elementos: un sistema semiótico común, un canal de conexión y una realidad exterior contextual, a la cual se atribuye una extensión objetiva y referencial.

Yong y Peng asumen y adaptan este modelo a las particularidades lexicográficas mediante la modificación de algunos de sus elementos:

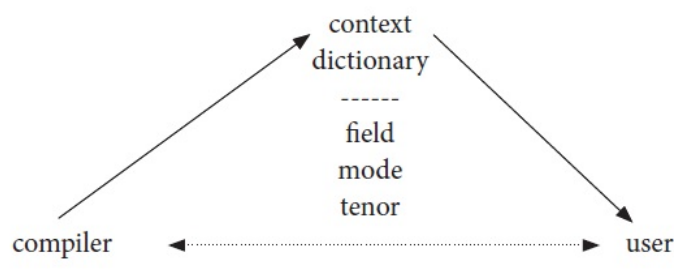

Figura 1. Modelo de comunicación lexicográfica de Yong y Peng (2007: 8) desarrollado a partir del modelo jakobsoniano.

En este modelo tres participantes conforman los tres vértices del triángulo comunicativo. El papel respectivo que estos desempeñan está unido por una flecha que indica la dirección de la influencia. La línea continua señala una influencia directa, mientras que la línea discontinua denota una influencia indirecta entre los participantes. En este punto Yong y Peng acomodan conceptos de la lingüística sistémico-funcional de Halliday (Halliday y Hasan 1989: 12-14). La estructura semiótica constitutiva del contexto en el cual se produce el intercambio y negociación de significados es representada en su modelo comunicativo por el diccionario, supeditado a su vez a factores situacionales - campo, modo y tenor- que lo determinan (Yong y Peng 2007: 23-81): el campo hace referencia al mensaje lexicográfico, en su sentido más amplio, que se pretende codificar y transmitir, al espectro temático que abarca y al área de conocimiento que le subyace. El modo designa el método, la técnica mediante la cual el mensaje es procesado, y aborda las cuestiones referentes a su codificación, organización y presentación, así como a través de qué canal y en qué medio se lleva a cabo la transmisión. El tenor es la relación entre el compilador y el usuario del diccionario en el acto comunicativo y el tipo de interacción que esta relación define entre ambos: ¿a qué tipo de usuario está destinado el diccionario? ¿Cuáles son sus expectativas y qué aspectos debe considerar el compilador para satisfacerlas? ¿Cuál es el papel del usuario en el proceso compilador? ¿Cómo va a influenciar el diccionario en los procesos y las estructuras de conocimiento del usuario?

La relevancia y el alcance de la conceptualización comunicativa postulada por Yong y Peng radica en la posibilidad de un desplazamiento de la perspectiva analítica, que se proyecta respectivamente desde el punto de vista del lexicógrafo, del usuario del diccionario y del contexto, sobre el mismo objeto de estudio lexicográfico. En este sentido, desde la óptica del compilador se abordan cuestiones relativas al sustrato teórico, la metodología o la funcionalidad, mientras que por parte del usuario se contemplan factores relacionados con la edad, formación, así como a un hipotético horizonte de expectativas. Desde la posición del contexto en el cual se ubica el proceso de compila- 
ción y elaboración del diccionario se evalúan aspectos como el tema o área de conocimiento tratado, la estructuración formal de los apartados y organización de la información, así como la selección del código conveniente.

\section{HACIA UN NUEVO MODELO DE COMUNICACIÓN LEXICOGRÁFICA}

La articulación metódica del potencial didáctico del diccionario en un marco teórico comunicativo representa un paso cualitativo de gran relevancia en la discusión e investigación lexicográfica. La revisión del marco de análisis elaborado por Yong y Peng que se propone en este artículo se materializa en una re-interpretación de las unidades de clasificación en función de la conceptualización del hecho comunicativo derivada del nuevo enfoque teórico. De este modo, sobre la base del marco clasificatorio de Yong y Peng, el planteamiento que aquí se presenta se aleja del empleo de esquemas interpretativos metafóricos y recurre, para una mejor comprensión y adecuado seguimiento de las implicaciones comunicativas del medio lexicográfico, al análisis de los principios teóricos y filosóficos de ambas escuelas (procesal y semiótica) en relación con la lógica del conocimiento subyacente: la lógica equivalencial y la lógica diferencial (Jung 2009: 27 y ss.).

La dicotomía lógica equivalencial - lógica diferencial aparece como un espacio de antagonismo, en el cual es posible reconocer una continuidad en la reflexión teóricofilosófica que subyace a la contraposición Modernidad - Postmodernidad, Estructuralismo - Postestructuralismo, etc. (Salas 2011; Bech 2000: 97 y ss.): los fundamentos teórico-epistemológicos que sustentan la Modernidad se articulan en torno a los principios positivistas - propios de las Ciencias Naturales - de una verdad racional, universal y objetiva. El modelo epistemológico positivista se propone la explicación (Erklären) mediante métodos cuantitativos de una realidad sometida a regularidades y leyes invariables. La Postmodernidad, por el contrario, se apoya en la tradición antipositivista (constructivista) - asociada a las Ciencias Sociales - de una verdad subjetiva, múltiple y contradictoria. Esta postura epistemológica se apoya en métodos cualitativos, con el fin, no de explicar, sino de comprender (Verstehen) e interpretar los fenómenos observados.

\subsection{Fundamentos teórico-filosóficos: lógica equivalencial vs. lógica diferencial}

Desde la óptica del binomio lógica equivalencial - lógica diferencial la definición de toda identidad significativa está sometida a dos principios dialécticos y deductivos discrepantes. Desde la perspectiva de la lógica equivalencial (Identitätslogik) se entiende la inmanencia de la identidad del conjunto como resultado de la suma de sus componentes. La lógica diferencial (Differenzlogik), por el contrario, concibe la diferencia como un factor constituyente per se, como un espacio de demarcación y al mismo tiempo de unión respecto a los componentes no-realizados en el sistema; la lógica diferencial se presenta como propuesta filosófica ante el pretendido fracaso de la lógica equivalencial en su intento de una descripción ontológica de la identidad (Jung 2009: 28). La crítica hacia las teorías esencialistas se dirige a su carencia de instrumentos analíticos adecuados para dilucidar las propiedades emergentes de un conjunto que revela más que la suma de sus componentes, ante lo cual la lógica diferencial postula la diferencia como elemento constituyente en sí mismo que convierte en prescindible la idea de identidad 
unitaria. Con arreglo a esta dualidad de análisis es posible ordenar las tres perspectivas presentadas por Yong y Peng en función de un planteamiento que explica el diccionario como obra de referencia en términos de la lógica de la equivalencia, mientras que la designación del mismo como texto y, más allá, como comunicación entra dentro de los modelos explicativos de la lógica diferencial.

\subsection{Diccionario como obra de referencia}

A la función referencial del diccionario en su concepción clásica subyace una definición esencialista del conocimiento. Bajo el término lógica equivalencial se entiende una conceptualización identitaria, la cual propugna una explicación de las propiedades inmanentes del sistema a partir de las propiedades de sus componentes (Jung 2009: 28). En esta tradición de pensamiento se localizaría el modelo de comunicación de Jakobson. El concepto general de la comunicación, según este modelo, asume los postulados esencialistas de la lógica del «lenguaje-objeto, que habla de objetos» (Jakobson 1981: 357), en la medida que se establece como un acto de transmisión, por parte de un «destinador» (352) a un destinatario, de un mensaje que denota un contexto de referencia concreto. Bajo el prisma de esta concepción tradicional, el diccionario como obra de referencia se corresponde con un listado ordenado según criterios determinados (generalmente alfabéticos) de elementos léxicos, sobre los cuales se ofrece al usuario una información explicativa y objetiva sobre un referente exterior.

\subsection{Diccionario como texto}

El pensamiento esencialista es sustituido por el pensamiento diferencial del postestructuralismo deconstructivista de Jacques Derrida (1967a, 1967b). El planteamiento de Derrida parte de una aparente irresolución conceptual en la Teoría del Valor del estructuralismo saussuriano. En palabras de Saussure, «en la lengua sólo hay diferencias sin términos positivos» (2009: 144); sin embargo, esta concepción saussuriana de la diferencia en el sentido de 'es distinto de' implica, según Derrida, la propia existencia de términos positivos ${ }^{2}$. Con el fin de resolver esta contradicción Derrida plantea su propuesta de pensar la diferencia en sí misma, concebida en cuanto momento dinámico en un espacio de separación - rehuyendo cualquier necesidad de términos positivos (v. Reichmann 2015: 28 y ss; Bertram 2002: 88-89).

Derrida sustituye la composición binaria del signo (significante y significado), en la cual se concede al significado un carácter presencial y transcendente, por una concepción tripartita que proyecta la diferencia en cuanto espacio vacío e intermedio, de ausencia. De acuerdo con Derrida, un signo no puede constituirse como tal sin su repetición, que implica a su vez la exclusión simultánea de otros signos posibles. La actualización de un signo genera en relación con su uso anterior un espacio de diferencia, i.e. un momento reflexivo, y traza a su vez una huella en el resto de signos de la estructura textual. En este sentido Derrida habla metafóricamente de huellas, que se repiten y que

${ }^{2}$ Saussure parece explicitar esta disonancia argumental cuando a continuación afirma que «decir que en la lengua todo es negativo sólo es verdad en cuanto al significante y al significado tomados aparte: en cuanto consideramos el signo en su totalidad, nos hallamos ante una cosa positiva en su orden» (2009: 144). 
se constituyen en el mismo momento de su impresión en relación con las ya trazadas (v. Bertram 2002: 87 y ss.). En el pensamiento de Derrida la presencia de cada uno de estos tres elementos - différance $e^{3}$, huella y repetición- es una conditio sine qua non para la constitución del signo, que tiene lugar sobre la base de su recurrencia en el seno de un tejido (del latín TEXTUS, participio de TEXERE, 'tejer, trenzar, entrelazar') de relaciones diferenciales entre huellas. Derrida justifica así la extensión de su concepción del texto a «prácticamente todo» ${ }^{4}$ más allá del soporte escrito. Para Derrida es posible hablar de texto en tanto en cuanto hay una diferencia referencial entre dos signos, y esta diferencia se encuentra en constante movimiento.

Sobre la base del enfoque formalista de sus teorías se perfila en la textualidad lexicográfica la relevancia conceptual del enfoque deconstructivista de Derrida. Su confrontación crítica con el logocentrismo filosófico - sobre cuyos cimientos se fundamenta la noción esencialista del significado léxico como entidad objetiva- socava la función tradicional del diccionario como obra de referencia. En consonancia con esta orientación textual, los diccionarios no materializan sino una red diferencial de elementos lingüísticos, cuyas huellas se refieren las unas a las otras en la forma de una «trama de significación» (Geertz 2003: 20). La cultura, según Geertz, se define en torno a un conjunto de tejidos discursivos que se organizan y estructuran en un sistema de significación, un con-texto de signos interpretables, dentro del cual pueden describirse de manera inteligible los acontecimientos sociales, los modos de conducta, las instituciones o procesos sociales (27).

Bajo esta perspectiva la red de significados presente en el medio lexicográfico queda englobada, más allá del contexto material del diccionario, en un con-texto más amplio que se compone a partir de las estructuras de significación constitutivas de la realidad socio-cultural. Esta noción de tejido textual de asociaciones, en el cual significado se constituye incesantemente en función de relaciones dinámicas y diferenciales, se contrapone a la idea tradicional del contexto como una realidad extra-textual, objetiva e invariable, referenciada en el medio lexicográfico.

\subsection{Diccionario como comunicación}

El concepto de diferencia representa el común denominador metodológico de las reflexiones semióticas de Derrida y de la Teoría General de Sistemas Sociales de Luhmann. El cuestionamiento que realiza Derrida del logocentrismo estructuralista ubica conceptualmente la diferencia en el plano de la forma material, del qué de la expresión; por el contrario, la diferencia como premisa fundamental del modelo de comunicación de Luhmann está orientada hacia cómo la nueva información es generada e integrada en

${ }^{3}$ Différance (en contraposición a la forma ortográficamente correcta différence) es un neologismo introducido por Derrida (1968) con el cual pretende conceptualizar la diferencia (i) en el espacio temporal entre un signo y su uso anterior, y (ii) en el espacio material, entre un signo y el resto de signos. El uso de la $a$, que únicamente puede distinguirse de la $e$ en su forma escrita y no en su pronunciación, denota la preeminencia que Derrida otorga a la escritura frente a la oralidad, en la medida que en la primera es posible evidenciar diferencias que son imperceptibles en la segunda (ibid.).

${ }^{4}$ Conversación con Derrida publicada por Engelmann en Semiotica Austriaca, Viena, 1987 (citado en Engelmann 1990: 20 y s.). 
la comunicación (comp. Marius y Jahraus 1997: 4). Esta reorientación hacia el proceso - desde el punto de vista de emergencia de la diferencia, frente al mecanicismo de la escuela procesal-, conduce a Luhmann a un distanciamiento de cualquier concepto de cultura o de texto. Luhmann sostiene que el término cultura en su alcance tradicional refleja «one of the most detrimental concepts ever to be invented» (Luhmann 2000a: 247), ya que impide la conformación de métodos de análisis adecuados para la descripción de la complejidad que va unida de un modo inseparable a la cualidad de las relaciones sociales (comp. 1998: 326). La categoría de textualidad, por otro lado, queda reducida a su dimensión material, en cuanto mero soporte material de la comunicación escrita (Gansel 2008: 12).

En el constructivismo sistémico-operativo de Luhmann la identidad sistémica no es unívoca e invariable, sino que se define in actus y solo está constituida por las continuas operaciones de selección que configuran el sistema y lo delimitan de su entorno. Un sistema se diferencia de su entorno en la medida en que transmuta complejidad externa en complejidad interna, y construye de esta manera su propio medio, en función de aquello que los principios de organización del sistema son capaces de discriminar del entorno y procesar (Luhmann 1996: 47 y ss.). La preservación y estabilidad del sistema en un proceso continuo de autogeneración requiere de unas estructuras que lo aseguren y regulen ${ }^{5}$ (Urteaga 2010: 314): «[u]na estructura consiste en la selección de posibilidades restringidas de puesta en relación de elementos, de modo que la incertidumbre inducida por el futuro se encuentre reducida». La «autorreferencia» (Selbstreferenz) caracteriza a los sistemas que derivan sus operaciones de sus propias operaciones, y determinan así las estructuras del sistema y con ello su propia interacción con el entorno (2000b: 7; 1996: 264) ${ }^{6}$. La «heterorreferencia» (Fremdreferenz) o referencia externa «a lo otro» (2000b: 7) se corresponde, de acuerdo con Luhmann, con la re-construcción o descripción del entorno a través del sistema ${ }^{7}$.

La teoría de la comunicación de Luhmann confronta los factores de la comunicación propuestos por Jakobson (emisor-mensaje-receptor) con una tríada informaciónemisión-comprensión, la cual se aparta de cualquier factor humano en el acto comunicativo. Según Luhmann comunicación se establece cuando un observador es capaz de

${ }^{5}$ La reproducción autorreguladora o autopoiética del sistema no resulta en una repetición idéntica de lo mismo - en este punto difiere Luhmann de la autoréplica en la analogía genética de Parsons (1973) —, sino en la creación constante de nuevos elementos, diferentes y, sin embargo, vinculados a los precedentes (v. Jensen 1999: 390-396).

${ }^{6}$ La autorreferencia luhmanniana se corresponde con el concepto de «determinación estructural» del constructivismo biológico de Maturana y Varela, según el cual las «perturbaciones» ocasionadas en un organismo vienen definidas por la configuración interna del mismo y no por «instrucciones» provenientes del entorno (2003: 64-67). En este sentido, la noción de autorreferencialidad en el lenguaje aparece reflejada en términos semejantes en los postulados de Anscombre y Ducrot (1983). Conforme a su Teoría de la Argumentación en la Lengua todo enunciado posee una capacidad argumentativa que le permite predisponer una serie de conclusiones en detrimento de otras. Esta orientación argumentativa vendría determinada en función de las estructuras morfosintácticas (tanto en la selección del léxico, como de las relaciones sintácticas) distintivas y propias de la lengua correspondiente.

${ }^{7}$ Este binomio conceptual autorreferencia - heterorreferencia presenta paralelismos con la idea de finalidad intralingüística («sprachinterne Zwecke») y finalidad extralingüística o situacional («sprachexterne Zwecke») de la Pragmática Funcional de Ehlich (2007: 59). 
distinguir entre emisión e información y, por lo tanto, de comprender la forma de la emisión como portadora de un contenido informativo y no como mera conducta (2005: 51). La operacionalización del espectro acústico como forma lingüística a modo de duplicado de la información situacional del entorno precisa, por lo tanto, del despliegue de una estructura o principio organizativo en forma de código (1998: 197). Esta codificación adquiere el formato de un código de carácter semiótico, $i$. e. una interfaz de correspondencia entre sonido y significado, que permite discernir en el continuum acústico la información del ruido, es decir, de los fenómenos acústicos no codificados (Krieger 1998: 22-23).

- Información-Emisión - Comprensión

Luhmann se aleja de la idea convencional de la linealidad del proceso de transmisión de la información y aboga por un modelo circular de retroalimentación ininterrumpida — «one cannot not communicate» (Watzlawick, Bavelas y Jackson 2011: 51)—, de procesamiento y actualización del sentido, basado en la percepción recíproca de las acciones. Luhmann adapta el Organonmodell de Bühler para la elaboración de un modelo que abstrae de la participación de agentes activos, emisor y receptor, como elementos constituyentes del acto comunicativo, e introduce en su lugar las variables impersonales ego y alter. La función apelativa es sustituida por la comprensión (Verstehen), que en la concepción de Luhmann alude a la capacidad de disociar entre el plano formal de la expresión y el plano de la información.

Con el único fin de autogenerarse y perpetuarse, el sistema de la comunicación requiere que las operaciones de diferenciación y selección que la definen sean constantes (comp. Urteaga 2010: 314). En el modelo de Luhmann se produce una selección de los tres componentes del acto comunicativo, tanto de la información, como de la emisión y de la comprensión. En primer lugar, se produce una selección de la información como referencia externa por parte de alter en la forma de una acción, situación o evento (1998: 390). Esta primera selección se realiza sobre la base de una relación de contraste, $i$. e. de novedad, con una situación anterior, lo que incentiva su re-producción en el plano formal de la emisión ${ }^{8}$. La selección de la forma de la emisión está a su vez vinculada con una autorreferencialidad. Esta referencialidad interna atribuye a un soporte material concreto, seleccionado entre un horizonte de posibilidades, un carácter autónomo en su función duplicativa de la información (1998: 102-106; Schützeichel 2003: 98-103). La fusión de ambos componentes, información y emisión, comporta una reduc-

${ }^{8}$ La importancia que esta desviación o relación de contraste adquiere en el hecho comunicativo queda reflejada en la Pragmática Inferencial de Sperber y Wilson (1995) basada en las máximas conversacionales de Grice (1989). Sperber y Wilson definen la relevancia como un rasgo esencial de la comunicación humana y que se mide en función de los «efectos cognitivos» (1995: 59, 153 y ss.) que una información nueva tiene sobre el conjunto de información ya existente. Conforme a esta Teoría de la Relevancia, una información será tanto más relevante cuanto más contribuya su valor comunicativo o informativo a modificar los conocimientos del individuo y su representación del mundo: «an input (a sight, a sound, an utterance, a memory) is relevant to an individual when it connects with background information he has available to yield conclusions that matter to him [...] According to relevance theory, an input is relevant to an individual when its processing in a context of available assumptions yields a positive cognitive effect. A positive cognitive effect is a worthwhile difference to the individual's representation of the world» (Wilson y Sperber 2006: 608). 
ción, y de esta manera, una «propuesta de sentido» de alter a ego (Luhmann 1997: 83, 1998: 203) ${ }^{9}$. La propuesta de sentido ofrecida por alter a través de la duplicación de la información situacional deviene en la constitución en la cadena hablada de una interfaz de correspondencia entre sonido e información que resulta en última instancia en una «homogeneización operativa» suficientemente estandarizada en forma de código empleado correspondientemente por alter y ego $(1998: 197)^{10}$. De esta manera la secuencia hablada se alza como «sistema de sentido» sobre el trasfondo de un espectro acústico semióticamente no codificado (v. Krieger 1998: 22-26). Esta codificación lingüística adquiere, por lo tanto, la forma de complejas estructuras que transponen la información situacional al plano de la expresión formal, y mediante las cuales es posible significar el evento codificado como información frente a la percepción acústica no codificada. La naturaleza de estas complejas estructuras de significación que establecen una relación entre el plano formal y el plano informativo es asimilable a los atributos de lo que conocemos como la gramática de una lengua (comp. Helbig 1998: 3).

Para la realización del hecho comunicativo resulta necesaria, en tercer lugar, la selección de la Comprensión por parte de ego. Esta se constituye en primer lugar como una «compresión estructural» (Sonnenburg 2007: 95) cuando ego es capaz de reconocer $\mathrm{y}$ distinguir entre un contenido informacional y una emisión formal ligada al mismo. La compresión estructural resulta del registro y asimilación por parte de ego de un binomio información-emisión dispuesto por alter. La comunicación se produce, por lo tanto, únicamente cuando un observador es capaz de discernir, en su ámbito de percepción, una emisión como forma estructurada, es decir, como portadora de una información determinada, y no solo como ruido, en un sentido más amplio, en cuanto fenómeno aleatorio de naturaleza física (Luhmann 2009: 54). En segundo lugar, y sobre la base de esta distinción, el acto de comprender se constituye como una extracción de sentido o «compresión del contenido» (Sonnenburg 2007: 95). El acto de comprensión se constituye de este modo como una selección contingente de sentido por parte de ego, que elige una opción en detrimento de otras, y que, sin embargo, se ve condicionada en función de la propuesta de sentido depositada en la conjunción de emisión e información ofrecida por alter (1998: 196-198; v. Jung 2009: 33).

Esta comprensión proporciona el requisito indispensable para el establecimiento de la comunicación: todo aquello que no es aprehendido en sus propiedades estructurales no puede ser percibido en su condición de evento codificado, sino como un suceso o estímulo físico carente de contenido informativo. El acto de comunicar se produce en sí mismo tan pronto como se constata una distinción entre una información y una emisión,

${ }^{9}$ El planteamiento que subyace al concepto de propuesta de sentido de Luhmann converge con la idea que sostienen Grice y Sperber y Wilson de que las emisiones despiertan expectativas de relevancia en el oyente/receptor que le encaminan hacia el sentido del enunciado (Wilson y Sperber 2006: 607 y s.).

${ }^{10}$ La etimología funcional defendida por Ehlich (2007) se aleja del estudio basado en la asociación tradicional forma-significado y se centra en el aspecto funcional-comunicativo del lenguaje: la constitución de estructuras lingüísticas de correspondencia forma-significado resulta de la relación de contraste entre la forma y su función comunicativa. De acuerdo con Ehlich, el imperativo de una organización estructural del continuum lingüístico, en la cual cada elemento asume múltiples funciones, nace de la necesidad de vincular un número restringido de realizaciones fonéticas con una casuística infinita de escenarios de aplicación (v. 2007: 96). 
con independencia de cualquier aprehensión de significado. El momento de comprensión (o incomprensión) en términos de contenido informativo se asimila a la asignación por parte de ego de una relación de significación entre la emisión y la información, en función de la aceptación o rechazo de la propuesta de sentido realizada por alter a través de su selección (1998: 120).

De acuerdo con Luhmann el observador de segundo orden comprende la forma de la emisión en cuanto conducta con unos objetivos e intenciones concretos ${ }^{11}$. Luhmann concibe la comunicación, por lo tanto, en una dimensión estrictamente funcional, de tal forma que sólo en la comunicación se constituye lo que comúnmente entendemos por «acción» (1998: 191 y ss.; comp. 1988: 10). Consecuentemente la comprensión queda, en consonancia con los planteamientos pragmatistas de Wittgenstein, desprovista de cualquier caracterización metafísica.

La consideración, sin embargo, de la comunicación en el modelo de Luhmann como «fenómeno emergente» (1998: 196) permite enlazar el substrato teórico de su modelo comunicativo con los planteamientos de la Psicología de la Gestalt ${ }^{12}$. Esta corriente dentro de la Psicología describe la percepción humana como la capacidad de identificar estructuras y principios organizativos en las percepciones sensoriales que no se constituyen como la simple adición de los datos percibidos. En este sentido, el trasfondo de la situación comunicativa actúa, en términos de la psicología gestáltica, como el armazón (framework) en el cual la expresión formal (figure) está «suspendida»; en consecuencia, la percepción de las propiedades morfológicas de la misma -tanto en sus aspectos conformativos (morfología lingüística) como configurativos o combinatorios (sintaxis)- queda determinada por la composición situacional comunicativa sobre la cual se sustenta (comp. Koffka 1936: 184). En otras palabras, la generación y las características del código dependen de la posición de la expresión formal percibida — diferenciada - sobre el fondo de la situación comunicativa concreta.

\section{LA COMPRENSIÓN INTRA-TEXTUAL}

A este respecto y en consonancia con los fundamentos constructivistas, el presente proyecto postula una nueva delimitación del valor referencial desde la extra-textualidad de la situación comunicativa a la intra-textualidad del diccionario (Gansel 2011: 63) ${ }^{13}$.

${ }^{11}$ Weber define la «acción social» como aquella conducta humana en la que el individuo que la produce la establece con ciertas «conexiones de sentido» (Sinnzusammenhang) y orientada a la conducta de terceros, frente a la mera conducta «reactiva», desligada de un sentido subjetivo (2002: 6 y ss.).

${ }^{12}$ Zeige (2011) refiere a los principios de la psicología gestáltica como uno de los fundamentos de la afinidad conceptual entre el modelo de comunicación de Luhmann y los modelos basados en el uso (usage-based models) de la Lingüística Cognitiva.

${ }^{13}$ En la misma línea, es posible asimilar el momento de la reducción o propuesta de sentido efectuada por alter en el modelo de Luhmann a la naturaleza indexical — del latin INDICARE, 'mostrar, señalar, dar a conocer'- constitutiva del texto lexicográfico. Kempson explica la función significativa de la indicación, la cual se despliega sobre una contextualización situacional concreta, «whereby the value that an expression has is dependent in some way to be analysed on the context in which it is uttered» (1988: 10). La indexicalidad caracteriza, por lo tanto, a aquellas expresiones formales que adquieren su significado dentro del contexto comunicativo de su enunciación. Este componente de indexicalidad se basa en la asociación directa de significación que el diccionario establece entre el lema y su descripción lexicográfica. 
La selección del elemento de referencia pasa de situarse en el plano de los eventos externos al diccionario a integrarse en la configuración de características textuales constitutivas del mismo. Esta transposición del valor referencial, desde la referencialidad externa a la autorreferencialidad, supone la reubicación del acontecimiento situacional observable en el plano de la proposición significable del discurso textual (Altmayer 2007: 12), esto es, en la descripción explicativa presentada en el artículo lexicográfico. De esta manera la propuesta de sentido se establece mediante la relación de contigüidad entre el lema o forma de la expresión y la información o explicación del contexto del cual emerge su significado. La funcionalidad comunicativa del diccionario se constituye así en una duplicación intra-textual de la configuración comunicativa extra-textual.

En este contexto de trasposición al plano de la exposición significable intra-textual de una realidad observable extra-textual, adquiere relevancia la subdivisión conceptual de la definición lexicográfica propuesta por Le Guern (2003) mediante la dicotomía entre el significado (signifié) de carácter lexical y autónomo de una realidad extralingüística, y la referencia (référence) asociada al conocimiento experiencial de un fragmento concreto de la realidad (31-47): el significado lexical de la palabra «lobo» contiene rasgos semánticos - «malvado», por ejemplo- que no constituyen rasgos substanciales pertinentes en el debate terminológico de la etología animal (rama de la biología que estudia el comportamiento de los animales) $(32)^{14}$.

En este punto, es posible identificar en la división propuesta por Le Guern la especificación de dos parámetros opuestos en un continuum que se extiende desde la autorreferencialidad asociada a las operaciones y las estructuras lingüísticas en el plano formal de la emisión hasta la referencialidad externa de la información. Hacia el ámbito de la emisión, la definición lexicográfica en cuanto significado lingüístico (signifié) estaría asociada a la orientación textual de Derrida, en consonancia con su planteamiento sobre la constitución tripartita del signo lingüístico en su relación diferencial con otros signos y carente de referencia a una realidad externa. Por el contrario, la consideración de la descripción lexicográfica como référence alude a una concepción de la definición lexicográfica desde el punto de vista de su función de anclaje referencial extralingüístico, es decir, en cuanto información situacional en consonancia con el enfoque de Luhmann. Esta disparidad de la pertinencia semiótica, entre un nivel estrictamente lingüístico y un nivel funcional-comunicativo, repercute indispensablemente en la diferente manera de enunciar la predicación (comp. Le Guern 2014: 166): Por un lado, la semiótica de los «textos-enunciados» inscritos en una arquitectura de significados y, por otro lado, la semiótica más próxima a un fragmento particular y concreto de la realidad, esto es, la de los «objetos» insertos a su vez en el marco más amplio de la «escena práctica» (166).

${ }^{14}$ Le Guern hace valer en el ámbito de la lexicografía la lógica analítica fregeana que establece una diferenciación conceptual dentro del significado: los predicados 'sol', 'astro rey' y 'único cuerpo celeste del sistema solar que emite luz propia' denotan la misma referencia (Bedeutung), difieren, sin embargo, en el sentido (Sinn) de las expresiones (Goldstein 2008: 85 y ss.). 


\section{CONCLUSIONES: ADQUISICIÓN DEL CÓDIGO GRAMATICAL EN EL DICCIONARIO}

La aplicación del modelo de comunicación de Luhmann —cuyos principios teóricofilosóficos se inscriben dentro de la lógica de la diferencia - permiten enlazar y armonizar argumentos relativos al proceso comunicativo y a la construcción del significado. Los aspectos esenciales de los enfoques procesal y semiótico quedan de esta manera actualizados e integrados en un modelo comunicativo de carácter psico-cognitivo. La aplicación de este modelo de comunicación al texto lexicográfico permite asimilar la tríada información - emisión - comprensión del modelo de Luhmann a las características estructurales del diccionario. De acuerdo con la tesis que propugna el presente artículo, los conceptos de emisión e información encontrarían su correspondencia orgánica en la dimensión vertical o macroestructural de las formas lemáticas y en la dimensión horizontal o microestructural de la descripción lexicográfica respectivamente (en este punto resulta interesante valorar la proximidad que se perfila en relación con el principio solidario referido por Saussure, tanto de «orden asociativo» como de «orden sintagmático» (2009: 156), el cual regula y limita la arbitrariedad del nexo entre la forma y el significado del signo lingüístico).

En consonancia con este planteamiento es posible situar el momento de la comprensión en la diferenciación estructural de ambas dimensiones presentada en el diccionario. En este sentido, el diccionario pone a disposición del usuario el marco que explicita el momento de la comprensión diferenciadora entre el plano formal y el plano del contenido. El momento de la comprensión, conforme al modelo de comunicación de Luhmann, queda configurado en una dimensión intra-textual dentro del marco lexicográfico, en la medida que la distinción presentada en el diccionario entre el plano formal de la expresión y el plano de la descripción informativa del contenido aparece a los ojos del usuario, en el momento de comprensión, como una síntesis única de sentido (v. 1998: 233-235).

Según lo expuesto anteriormente y en el contexto lexicográfico que nos ocupa, es posible afirmar que el código gramatical emerge - en cuanto estructura gestáltica percibida- en el plano de intersección entre la dimensión vertical de las formas léxicas - figure - dispuestas en la macroestructura y la dimensión horizontal de la referencia funcional-informativa - framework - del artículo. La superposición de ambas dimensiones resulta en la inferencia o interiorización implícita del código subyacente o interfaz de correspondencia entre la forma y el significado, esto es, de la gramática. La concepción del conocimiento lingüístico-gramatical que subyace a la tesis expuesta en este artículo se inscribe, por lo tanto, dentro de una orientación holística y experiencial, de carácter dinámico, emergente y no-proposicional, frente a una concepción modular e innatista del mismo, en cuanto cálculo lógico-combinatorio de variables discretas de significación sometidas a un conjunto de reglas (v. Schwarz 2008: 46 y ss.).

De conformidad con el reconocimiento que otorga Stein a la función del diccionario en cuanto «silent language teacher» (1984: 126) renombrados lexicógrafos han constatado la necesidad apremiante de un giro en la orientación didáctica del diccionario, cuya concepción se encuentre motivada desde el punto de vista de la psicología del aprendizaje (Kühn 1989: 120; Kempcke 1992: 172; v. Zöfgen 1994: 20). En esta línea, el modelo de comunicación lexicográfica propuesto en este artículo permite la integración en la 
investigación lexicográfica de modelos psico-cognitivos del aprendizaje-enseñanza de la lengua (Butzkamm 2002, 2004, 2008; Cook, 1992, 2008), y abre de esta manera el camino hacia la consideración y la utilización de la configuración macro- y microestructural del diccionario como un meta-medio de carácter reflexivo al servicio del usuario estudiante de la lengua extranjera como una herramienta útil para la adquisición e interiorización de los mecanismos de producción del lenguaje.

\section{REFERENCIAS BIBLIOGRÁFICAS}

AgUADO, Juan Miguel (2004): Introducción a las teorías de la comunicación y la información, Murcia, Editorial DM.

AltMAYER, Claus (2007): «Von der Landeskunde zur Kulturwissenschaft. Innovation oder Modetrend?», Germanistische Mitteilungen, 65, pp. 7-21.

ANSCOMBRE, Jean-Claude y Oswald DUCROT (1983): L'argumentation dans la langue, Brussels, Mardaga.

BECH, Josep M. (2000): La filosofia y su historia, Barcelona, Universidad de Barcelona.

Bertram, Georg (2002): Hermeneutik und Dekonstruktion. Konturen einer Auseinandersetzung der Gegenwartsphilosophie, München, Wilhelm Fink.

ButzKamm, Wolfgang (2002): Psycholinguistik des Fremdsprachenunterrichts. Von der Muttersprache zur Fremdsprache, Tübingen, Francke.

ButZKAMM, Wolfgang (2004): Lust zum Lehren, Lust zum Lernen. Eine neue Methodik für den Fremdsprachenunterricht, Tübingen, Francke.

ButZKAMM, Wolfgang (2008): Wie Kinder sprechen lernen. Kindliche Entwicklung und die Sprachlichkeit des Menschen, Tübingen, Francke.

COOK, Vivian J. (1992): «Evidence for Multicompetence», Language Learning, 42(4), pp. 557-591.

CoOK, Vivian J. (2008). Second language learning and language teaching, London, Hodder Education.

DERRIDA, Jacques (1967a): De la Grammatologie, Paris, Les Éditions de Minuit.

DERRIDA, Jacques (1967b): L'écriture et la différence, Paris, Éditions du Seuil.

DERRIDA, Jacques (1968): «La différance», en M. Foucault, R. Barthes, J. Derrida et al., Theorie d'emsemble, Paris, Éditions du Seuil, pp. 41-66.

ECO, Umberto y Paolo FABBRI (1978): «Progetto di ricerca sull'utilizzazione dell'informazione ambientale», Problemi dell'informazione, IV, pp. 555-597.

EHLICH, Konrad (2007): Sprache und sprachliches Handeln, Berlin, De Gruyter.

EngelmanN, Peter (1990): «Postmoderne und Dekonstruktion. Zwei Stichwörter zur zeitgenossischen Philosophie», en P. Engelmann, ed., Postmoderne und Dekonstruktion. Texte französischer Philosophen der Gegenwart, Stuttgart, Reclam, pp. 5-32.

FISKE, John (1982): Introducción al estudio de la comunicación, Bogotá, Norma.

FRAWLEY, William (1989): «The Dictionary as Text», International Journal of Lexicography, II, 3, pp. 231-248. 
GANSEL, Christina (2008): «Systemtheoretische Perspektiven auf Textsorten. Vorbemerkungen», en C. Gansel, ed., Textsorten und Systemtheorie, Göttingen, V \& R Unipress, pp. 7-20,

GANSEL, Christina (2011): Textsortenlinguistik, Göttingen, Vandenhoeck \& Ruprecht.

GEERTZ, Clifford (2003): La interpretación de las culturas, Barcelona, Gedisa.

GreEnBlatT, Stephen (1988): Shakespearean Negotiations. The Circulation of Social Energy in Renaissance England, Berkeley, University of California Press.

GRICE, Paul (1989): «Logic and conversation», en P. Grice, ed., Studies in the Way of Words, Cambridge, Harvard University Press, pp. 22-40.

Goldstein, Lawrence (2008): Lógica. Conceptos clave en Filosofía, Valencia, Universitat de València.

HALLIDAY, Michael Alexander K. y Ruqaiya HASAN (1989): Language, context and text. Aspects of language in a social-semiotic perspective, Hong Kong, Deakin University.

HELBIG, Gerhard (1998): «Zum Verhältnis zwischen Grammatik und Lexikon», en I. Barz, ed., Zwischen Grammatik und Lexikon, Tübingen, Niemeyer, pp. 1-10.

JAKOBSON, Roman (1981): «Lingüística y poética», en Ensayos de lingüística general, Barcelona, Seix Barral, pp. 347-395.

Jensen, Stefan (1999): Erkenntnis - Konstruktivismus - Systemtheorie. Einführung in die Philosophie der konstruktivistischen Wissenschaft, Opladen, Westdeutscher Verlag.

JunG, Arlena. (2009): Identität und Differenz. Sinnprobleme der differenzlogischen Systemtheorie, Bielefeld, Transcript.

KEMPCKE, Günter (1992): «Organisationsprinzipien und Informationsangebote in einem Lernerwörterbuch», en U. Brauße y D. Viehweger, eds., Lexikontheorie und Wörterbuch. Wege der Verbindung von lexikologischer Forschung und lexikographischer Praxis, Tübingen, Niemeyer, pp. 165-244.

KEMPSON, Ruth M. (1988): «The relation between language, mind, and reality», en R. M. Kempson, ed., Mental representations. The interface between language and reality, Cambridge, Cambridge University Press, pp. 3-25

KRIEGER, David J. (1998): Einführung in die allgemeine Systemtheorie, München, Fink.

KÜHN, Peter (1989): «Typologie der Wörterbücher nach Benutzungsmöglichkeiten», en F. J. Hausmann, O. Reichman, H. E. Wiegand y L. Zgusta, eds., Handbücher zur Sprach- und Kommunikationswissenschaft. Wörterbücher. Ein internationales Handbuch zur Lexikographie, Berlin, De Gruyter, pp. 111-127.

Kunn, Thomas S. (1962): The Structure of Scientific Revolutions, Chicago, University of Chicago Press.

LAKOFF, George y Mark JOHNSON (1980): Metaphors We Live By, Chicago, University of Chicago Press.

LE GUERN, Michel (2003): Les deux logiques du langage, Paris, Champion.

LE GUERN, Odiel (2014): «El principio de inmanencia, entre el paratexto y el intertexto». Tópicos del Seminario, XXXI, Puebla, Universidad Autónoma de Puebla, pp. 161174.

LUHMANN, Niklas (1988): «Was ist Kommunikation?», en F. B. Simon, ed., Lebende Systeme. Wirklichkeitskonstruktionen in derSystemischen Therapie, Berlin, Springer, pp. 10-19. 
LUHMANN, Niklas (1997): Die Gesellschaft der Gesellschaft, Frankfurt am Main, Suhrkamp.

LuHMANN, Niklas (1998): Sistemas sociales. Lineamientos para una teoría general, Barcelona, Anthropos.

LUHMANN, Niklas (2000a): Art as a social system, Standford, Standford University Press.

LuHMANN, Niklas (2000b): La realidad de los medios de masas. Barcelona, Anthropos.

LuHMANN, Niklas (2005): «Die Gesellschaft als soziales System», en D. Baecker, ed., Einführung in die Theorie der Gesellschaft, Heidelberg, Carl-Auer, pp. 11-86.

LuHMANN, Niklas (2009): Soziologische Aufklärung. Konstruktivistische Perspektive, Wiesbaden, VS Verlag.

MARIUS, Benjamin y Oliver JaHraus (1997): Systemtheorie und Dekonstruktion. Die Supertheorien Niklas Luhmanns und Jacques Derridas im Vergleich, Siegen, Lumis.

Maturana, Humberto y Francisco VAREla (2003): El árbol del conocimiento. Las bases biológicas del entendimiento humano, Buenos Aires, Lumen.

PARsons, Talcott y Gerald M. PlatT (1973): The American University, Cambridge, Harvard University Press.

SALAS, Héctor (2011): «Investigación Cuantitativa (Monismo Metodológico) y Cualitativa (Dualismo Metodológico): El status epistémico de los resultados de la investigación en las disciplinas sociales», Cinta de Moebio, 40, pp. 1-21.

SAUSSURE, Ferdinand de (2009): Curso de lingüistica general, Madrid, Akal.

SCHÜTZEICHEL, Rainer (2003): Sinn als Grundbegriff bei Niklas Luhmann, Frankfurt am Main, Campus.

SCHWARZ, Monika (2008): Einführung in die kognitive Linguistik, Tübingen, Francke.

SONNENBURG, Stephan (2007): Kooperative Kreativität. Theoretische Basisentwürfe und organisationale Erfolgsfaktoren, Berlin, Springer.

SPERBER, Dan y Deindre WILSON (1995): Relevance. Communication and Cognition, Oxford, Blackwell.

URTEAGA, Eguzki (2010): «La teoría de sistemas de Niklas Luhmann», Contrastes. Revista Internacional de Filosofía, XV, pp. 301-317.

WATZlawick, Paul, Janet Beavin BAVELAS y Don de Avila JACKSON (2011): Pragmatics of Human Communication: A Study of Interactional Patterns, Pathologies and Paradoxes, New York, W. W. Norton \& Company.

YONG, Heming y Jing PENG (2007): Bilingual Lexicography from a Communicative Perspective, Amsterdam, John Benjamins.

WeBER, Max (2002): Economía y sociedad. Esbozo de sociología comprensiva, México D.F., Fondo de Cultura Económica.

WILSON, Deirdre y Dan SPERBER (2006): «Relevance Theory», en L. R. Horn y G. Ward, eds., The Handbook of Pragmatics, Oxford, Blackwell, pp. 607-632.

ZEIGE, Lars Erik (2011): «On cognition and communication in usage-based models of language change», en D. Coussé y F. von Megden, eds., Usage-Based Approaches to Language Change, Amsterdam, John Benjamins, pp. 49-80.

ZÖFGEN, Ekkehard (1994): Lernerwörterbücher in Theorie und Praxis. Ein Beitrag zur Metalexikographie mit besonderer Berücksichtigung des Französischen, Tübingen, Niemeyer. 


\section{TÍTULO/TITLE}

«Hacia un nuevo modelo de comunicación lexicográfica en el ámbito de la adquisición de lenguas extranjeras» «Towards a new model of lexicographical communication in the field of SLA»

Fecha de recepción: 15/03/2017 Fecha de aceptación: 29/01/2018

Resumen: Las consideraciones expuestas en este artículo tienen como objetivo ampliar la discusión en torno a la adquisición del lenguaje sobre los fundamentos de la teoría de la comunicación. Sobre esta base, se propone una integración del modelo de comunicación de Luhmann en el marco teórico de la lexicografía aplicada al aprendizaje de lenguas (diccionarios monolingües). La relevancia de este modelo diferencialista de la comunicación reside en la conceptualización de la gramática en cuanto código emergente; en este sentido, se argumentará que, desde este punto de vista cognitivo, la estructura lexicográfica que sostienen el acto de comunicación ostenta la capacidad, en virtud de sus propiedades mediales, de revelar este código gramatical y activar de manera implícita la adquisición de la gramática en el usuario del.

Palabras clave: comunicación lexicográfica; Luhmann; lógica diferencial; modelo de comunicación; código gramatical; adquisición del lenguaje.

Abstract: The considerations laid out in this article aim to broaden the discussion concerning language acquisition on the foundations of the theory of communication. On that basis, this contribution proposes an integration of Luhmann's model of communication in the theoretical framework of SLALexicography (monolingual learner dictionaries). The relevance of this differentialist model lies in its ability to conceptualize grammar as an emergent code. In this regard, it will be argued that, from a cognitive point of view, the lexicographic structure supporting this act of communication may be capable, by virtue of its medial properties, of revealing this grammatical code and implicitly activating grammar acquisition in the dictionary user's perception.

Keywords: lexicographical communication; Luhmann; differentialist logic; communication model; grammatical code; language acquisition. 